\title{
OPTIMIZING THE SHAPE OF A COMPRESSION-IGNITION ENGINE COMBUSTION CHAMBER BY USING SIMULATION TESTS
}

\author{
Ireneusz Pielecha \\ Jerzy Merkisz \\ Poznan University of Technology, Poland
}

\begin{abstract}
Modern solutions used in compression-ignition internal combustion engines are quite similar to each other. The use of high-pressure, direct fuel injection results in high combustion rates with controlled exhaust emissions. One of the combustion system quality criteria is to obtain adequately high thermodynamic indicators of the combustion process, which are obtained through, among others, the right combustion chamber geometry. Its shape influences the fuel atomization process, turbulence of fuel dose, evaporation and the combustion process. Optimizing the combustion chamber shape is one of the decisive factors proving the correct execution of the combustion process. This article presents the methodology of choosing the combustion chamber shape (changes of three selected combustion chamber dimensions) by using the optimization methods. Generating multidimensional data while maintaining the correlation structure was performed by using the Latin hypercube method. Chamber optimization was carried out by using the Nelder-Mead method. The combustion chamber shape was optimized for three engine load values (determined by the average indicated pressure) at selected engine operating conditions. The presented method of engine combustion chamber optimization can be used in low and high speed diesel propulsion engines (especially in maritime transport applications).
\end{abstract}

Keywords: CI engine combustion system, combustion process thermodynamic analysis, combustion chamber optimization

\section{INTRODUCTION}

The internal combustion engine design quality is defined by its operational indicators. Currently the engine capability of meeting the emission limits can be considered an additional indicator of structure quality. These two indicators mean that internal combustion engines must meet various, often widely different requirements.

The operating indicators for four-cycle low-speed internal combustion engines are currently rather large. The average indicated pressure of two-stroke engines is about 2.1 $\mathrm{MPa}$ with a specific fuel consumption value (dual fuel mode methane injection) of $129 \mathrm{~g} / \mathrm{kWh}$ (i.e. MAN B\&W G35MEC10.5-GI). The brake mean effective pressure (BMEP) of four-stroke engines ranges from 2.25 $\mathrm{MPa}$ with a specific fuel consumption (SFC) of $186 \mathrm{~g} / \mathrm{kWh}$ (gas mode) (i.e. MAN
$\mathrm{L} 51 / 60 \mathrm{DF})$ up to $2.83 \mathrm{MPa}$ at SFC reaching $175.5 \mathrm{~g} / \mathrm{kWh}$ $(\mathrm{n}=720 \mathrm{rpm})$ (i.e. MAN L32/44CR) [7].

Compression-ignition engines also gain slightly higher values. The Wartsila 31 engine has a BMEP of $3.1 \mathrm{MPa}$ (at $\mathrm{n}=750 \mathrm{rpm}$ ) and a power of $610 \mathrm{~kW} / \mathrm{cyl}$. [15].

One of the main systems responsible for the internal combustion engine design quality is the combustion system along with the fuel supply system. The main problem in that case is the shape of the combustion chamber. Its shape and dimensions depend on the method of fuel injection and atomization, the fuel dose turbulence size, and the combustion process. The formation of exhaust components, with particular focus on the nitrogen oxides and solid particles emission, is an important aspect of the combustion chamber shape. The use of dual-fuel (liquid and gas fuels) combustion systems [11] does not allow to fully optimize this structure, as it would 
necessitate meeting requirements related to different fuel properties that are at times in opposition to each other. The use of fuel additives [10] also allows to control the combustion process, but to a lesser extent than the optimal shape of the combustion chamber.

\section{IMPACT OF THE COMBUSTION CHAMBER SHAPE ON ENGINE OPERATING INDICATORS}

Experimental research on combustion chamber optimization in stationary CI engines was carried out by Vedharaj et al. [14]. The impact of the trapezoidal and toroidal chamber (one cylinder, four stroke engine ( $\mathrm{S} \times \mathrm{D}-87.5 \times 110 \mathrm{~mm}$ ) using the Kapok methyl ester and diesel blend (KME - diesel blends) was tested. As a result, it was found that exhaust emission can be reduced by using the TCC (toroidal combustion chamber) and an increase of the BTE (brake thermal efficiency) can be reached.

Similar studies with using the chambers: Hemispherical, Straight Sided, Toroidal and Re-entrant Toroidal were conducted by Channappagoudra et al. [2] powering the CI engine with the B20 fuel. The best parameters of engine operation and exhaust emission indicators were obtained by using the Re-entrant Toroidal chamber.

Experimental studies along with model ones were conducted by Khan et al [5]. He analyzed the experimental Hemispherical chamber and development of the fuel stream and compared the tests with theoretical models containing the Toroidal Re-entrant (TR) and standard toroidal chamber. Simulation results show that spray angle significantly affects the mixing and combustion process for all three bowl geometries and that the engine having TR combustion chamber gives better performance (generate a strong squish and turbulence).

Simulations of the combustion chamber shape were carried out by Gaffor and Gupta [3]. Using the rectangular shape of the combustion chamber, they showed that a low $\mathrm{d} / \mathrm{D}$ ratio (bowl diameter to cylinder diameter) increases NO emission and decreases soot emission due to the high combustion rate within TDC.

Similar simulation research on combustion chamber optimization was conducted by Navid et al. [9] and Taghavifar [13]. The results of the works relate to high compression ratios (19.5:1). The exhaust emission values were not analyzed in these works. In [9] several optimization methods were compared and a high similarity of the obtained results was noted.

\section{AIM AND SCOPE OF RESEARCH WORK}

The aim of the simulation research is to find the combustion chamber shape which exhibits the maximum indicator values of thermodynamic process in the form of the brake mean effective pressure. It is possible to choose a different indicator, however, in traction applications of low-speed internal combustion engines, the requirements concerning exhaust emissions are not the ones which play the most important role.
For this reason, an indicator has been chosen which allows to make significant changes in the shape of the combustion chamber (by changing selected quantities of its shape).

The scope of the work related to optimization concerns: 1) pressure analysis in the combustion chamber, 2) heat dissipation rate, 3) total heat released, 4) change of excess air coefficient, 5) indicated engine efficiency, 6) mechanical efficiency and 7) exhaust emission analysis of the combustion process (NO and soot emission).

\section{RESEARCH METHODOLOGY}

\section{COMBUSTION CHAMBER GEOMETRY}

For simulation analysis an example (typical) combustion chamber of a CI engine was chosen. The scope of the simulation work concerned the change of the following design variables (Fig. 1):

- Combustion chamber radius - R3,

- Distance between the piston and the engine head - TDC,

- The depth of the combustion chamber at its centre - Tm in order to obtain the maximum indicated mean effective pressure - IMEP.

As a result of changing the listed values, the combustion process itself changes due to the fuel dose preparation process being altered (change of compression ratio due to the change in the combustion chamber size, resulting in different compression pressure values during ignition, with consequences in the form of thermodynamic and emission impact of the process).

\section{THE BOUNDARY AND INITIAL CONDITIONS OF THE SIMULATIONS}

The simulation tests were carried out in typical operating conditions of a medium-speed engine (such as a marine engine) by using the AVL FIRE software [1]. The characteristics of engine geometry are presented in Tab. 1. The initial and boundary conditions of the simulation tests are listed in Tab. 2. The thermodynamic gas characteristics during compression were provided and the used calculation models described. Important data regarding fuel injection are presented in Tab. 3 .

Tab. 1. Characteristics and parameters of the engine used in simulations

\begin{tabular}{|c|c|c|c|}
\hline No. & Parameter & Unit & Value \\
\hline 1. & Number of cylinders & - & 1 \\
\hline 2. & S x D & $\mathrm{mm} \mathrm{x} \mathrm{mm}$ & $85 \times 90$ \\
\hline 3. & Connecting rod length & $\mathrm{mm}$ & 94 \\
\hline 4. & $\varepsilon$ (initial) & - & 16 \\
\hline
\end{tabular}




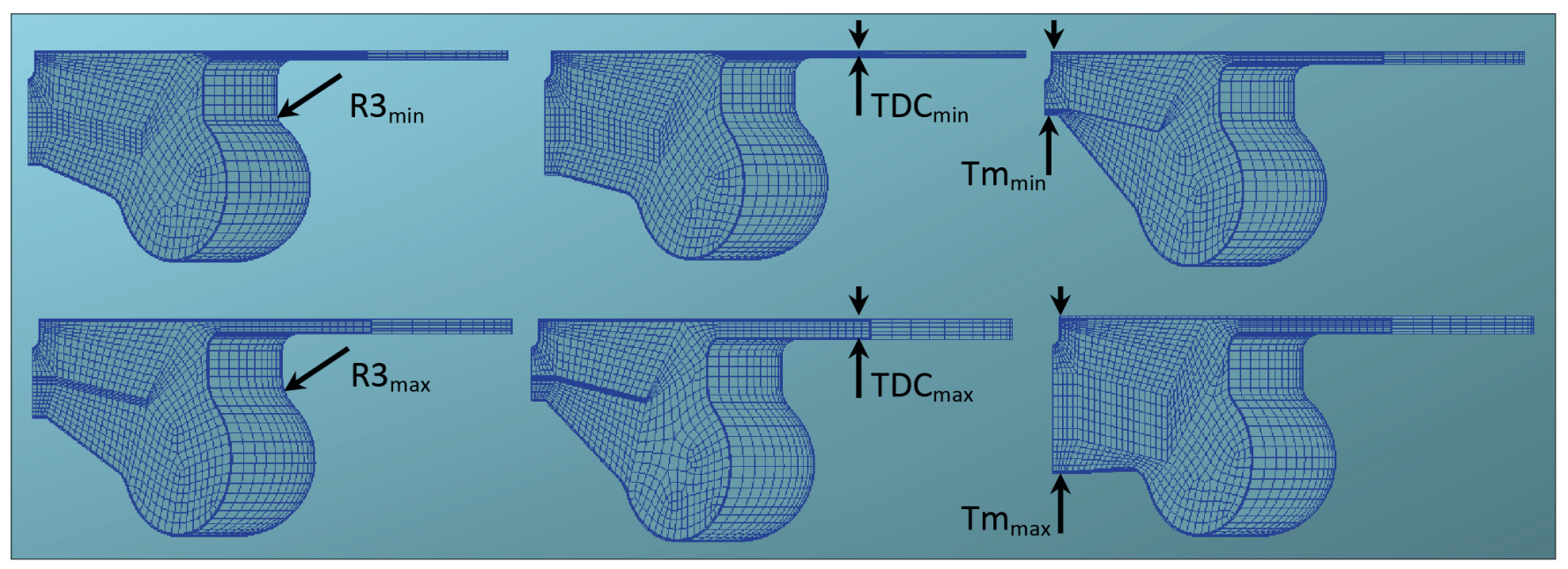

Fig. 1. Combustion chamber shape with changing design variables

Tab. 2. Simulation parameters

\begin{tabular}{|c|c|c|c|}
\hline No. & Description & Unit & Value \\
\hline 1. & Engine speed & $\mathrm{rpm}$ & 1000 \\
\hline 2. & Start of simulation & $\operatorname{deg}$ & 540 \\
\hline 3. & End of simulation & $\operatorname{deg}$ & 800 \\
\hline 4. & Initial cylinder pressure & $\mathrm{MPa}$ & 0.15 \\
\hline 5. & $\begin{array}{l}\text { Initial fuel dose temperature } \\
\text { in the cylinder }\end{array}$ & $\mathrm{K}$ & 380 \\
\hline 6. & $\begin{array}{c}\text { Initial wall temperature: piston } \\
\text { liner } \\
\text { head }\end{array}$ & $\begin{array}{l}\mathrm{K} \\
\mathrm{K} \\
\mathrm{K}\end{array}$ & $\begin{array}{l}575 \\
475 \\
550\end{array}$ \\
\hline 7. & $\begin{array}{l}\text { Initial turbulent kinetic energy } \\
\text { (TKE) }\end{array}$ & $\mathrm{m}^{2} / \mathrm{s}^{2}$ & 10 \\
\hline 8. & Initial turbulent length scale & $\mathrm{m}$ & 0.003 \\
\hline 10. & Breakup model & \multicolumn{2}{|c|}{ Wave } \\
\hline 10. & Evaporating model & \multicolumn{2}{|c|}{ Dukowicz } \\
\hline 9. & Wall model & \multicolumn{2}{|c|}{ Walljet1 (Naber\&Reitz) } \\
\hline 10. & Combustion model & \multicolumn{2}{|c|}{$\begin{array}{l}\text { Coherent Flame Model: } \\
\text { ECFM-3Z } \\
\text { Autoignition: Two-stage }\end{array}$} \\
\hline 10. & Model NO & \multicolumn{2}{|c|}{ Extended Zeldovich } \\
\hline 11. & Soot model & \multicolumn{2}{|c|}{ Kinetic Model } \\
\hline
\end{tabular}

Tab. 3. Fuel injection conditions

\begin{tabular}{|c|c|c|c|}
\hline No. & Parameter & Unit & Value \\
\hline 1. & Start of injection (SOI) & $\mathrm{deg}$ & 719 \\
\hline 2. & Injection time & $\mathrm{ms}$ & 1 \\
\hline 3. & Fuel mass & $\mathrm{mg}$ & $12 ; 20 ; 40$ \\
\hline & Fuel temperature & $\mathrm{K}$ & 330.15 \\
\hline
\end{tabular}

In the wave disintegration model of the droplet the initial increase in turbulence on the fluid surface is used along with the increase in the wavelength and other physical and dynamic parameters of the injected fuel. Two disintegration systems can be distinguished: for small and high speeds. The Dukowicz model was used to simulate evaporation of fuel droplets [1]. It is based on typical coefficients of heat and mass exchange, with the assumptions that 1 ) the spheres are symmetrical, 2) the film on the surface of fuel drops is quasi-permanent, 3) the temperature of the droplets is uniform along its diameter, and 4) the drop surface is in a thermal liquid-gas balance. Walljet model (wall model) is based in principle on the spray/wall impingement model of Naber and Reitz [8]. The concept is that in the working engine conditions a vapor cushion is formed under the droplets and that they rebound or slide along the walls. The ECFM combustion model (Extended Coherent Flame Model) applies to a turbulent premixed combustion regime, using a chemical time scale, integral length scale and turbulence intensity. The extended Zeldowicz model concerns the formation of nitrogen oxides through three reactions: $\mathrm{N}_{2}+\mathrm{O} ; \mathrm{N}+\mathrm{O}_{2}$ and $\mathrm{N}+\mathrm{OH}[1,4]$. The basis of the kinetic model (soot model) is a detailed chemical reaction scheme for the calculation of soot formation and oxidation (the complete model contains over 100 reactions; 7 oxidation reactions of various hydrocarbons have been implemented in AVL Fire software) [1].

\section{METHOD OF GENERATING MULTIDIMENSIONAL DATA}

By using the DVI (Design Variation Interface) module of the AVL Fire software, the design variables of the following basic values have been assigned:

R3 $-0.00242857 \mathrm{~m}$ (variation $\pm 50 \%$ ),

$\mathrm{Tm}-0.00121429 \mathrm{~m}$ (variation $\pm 50 \%)$,

TDC $-0.00886429 \mathrm{~m}$ (variation $\pm 50 \%$ ).

To generate multidimensional data while maintaining the correlation structure, the Latin-Hypercube method was used [12]. This method divides the design space of every 
factor $n$ (each variable) evenly into 10 levels. There is only one point on each project ? level. In the columns of the designed matrix there are $n_{k}$ combinations with the same probability of occurring. Because the matrix is randomly generated, there may be a correlation between the columns. The structure associated with 10 research samples was used for the analysis (Fig. 2).

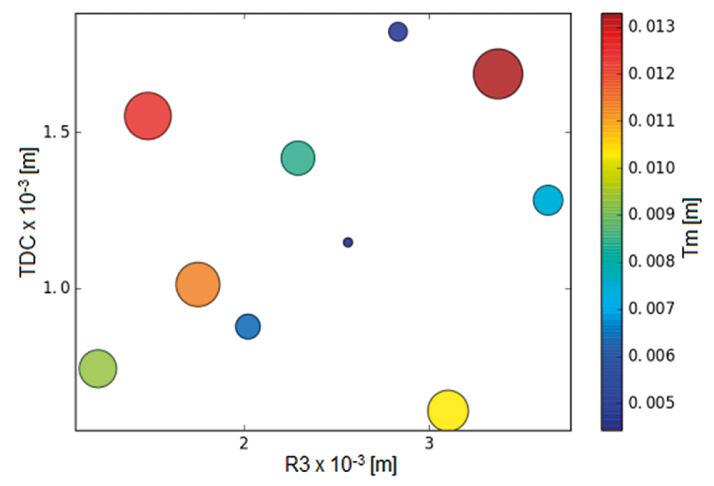

Fig. 2. The method of selecting initial data for optimization of three variables $-2 D$ view

The initial data generated this way was subject to further optimization.

\section{OPTIMIZATION PROCEDURE}

The optimization task was based on the Nelder-Mead method (downhill simplex method) [6]. To simplify: it consists of a gradual transformation of the simplex (in the threedimensional space it is a tetrahedron) in such a way that in each next iteration the worst point can be replaced with a specially created new one.

In the optimization task, the target function (maximization of average indicated pressure) takes the form:

$$
\mathrm{f}(\mathrm{R} 3, \mathrm{Tm}, \mathrm{TDC})=\max
$$

where the starting values of design variables and their variability ranges (restrictions) are as given previously.

The generated starting data (10 solutions) and optimization conditions created more than 20 configurations of combustion systems, whose target function was maximized (max IMEP).
The research was carried out by using the ESE Diesel software from the AVL Fire package [1]. For each case, a new mesh was generated and calculations were made for modification of design variables (R3, Tm, TDC) in the range of 540 to $800 \mathrm{deg}$ on the crankshaft. Changes in the shape of the combustion chamber resulted in thermodynamic changes (with special regard to IMEP as a target function) and emission changes for these combustion processes.

\section{OPTIMIZATION OF THE COMBUSTION CHAMBER IN THE ASPECT OF ENGINE LOAD}

The analysis of optimal solutions was carried out individually for each engine load value. The assessment of optimal design variables indicates that the variation of the variables depends on the engine load (Fig. 3). The largest differences were obtained for changes in the value of the variable $\mathrm{R} 3$, where, with increasing engine load, the optimal value of this variable is not predictable.

A complete analysis of changes in the design variable values is presented in Fig. 4. It shows that increased load requires:

a) reducing the size of radius $\mathrm{R} 3$,

b) reducing the TDC value

and an undefined change in the size of Tm (average engine load causes a drop of this value - Fig. $4 \mathrm{~b}$, while other loads increase it). Analysis of changes in the search for individual variables (Fig. 4) indicates the same directions of changes of these values regardless of the load. However, the obtained results of the target function are not similar. The first 10 attempts created on the basis of the Latin hypercube are the same (same values of design variables), which does not result in identical changes of the target function. For this reason, point 11 (Fig. 4) is similar to the values of design variables leading to the maximization of the target function in the first ten attempts.

The combustion chamber optimization should result in different values of compression and combustion pressure. Such conditions should also cause differential thermodynamic properties of the combustion process and exhaust emissions. Their analysis was carried out in the next part of the article.
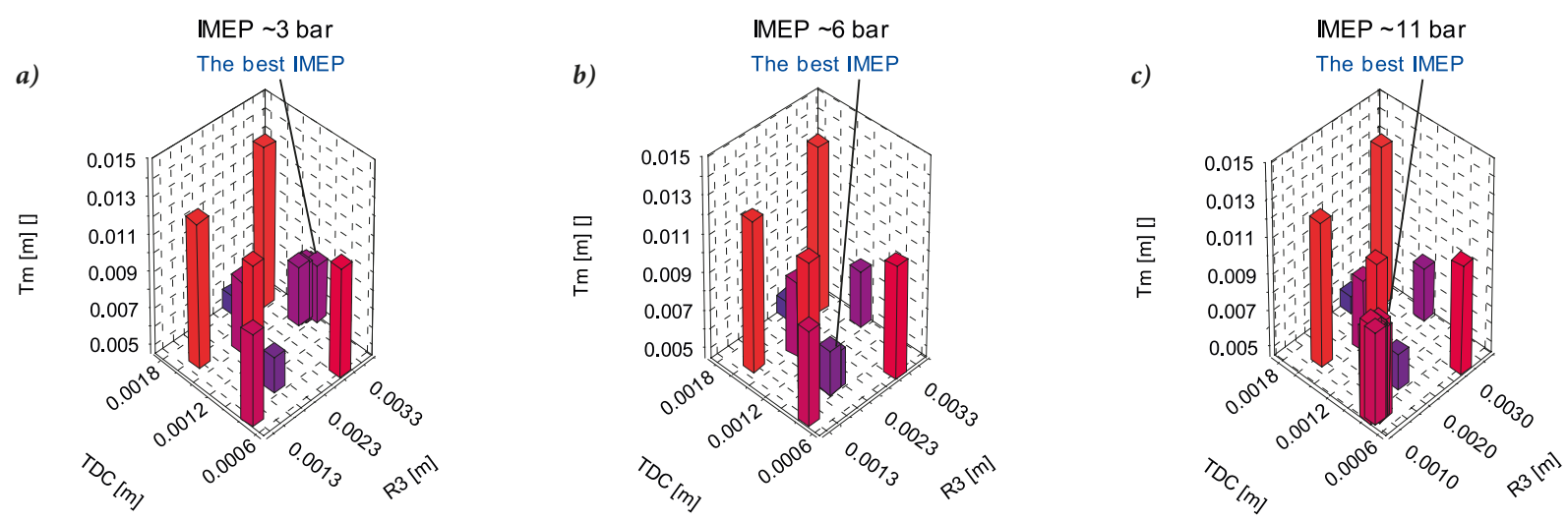

Fig. 3. Three-dimensional layout of operational indicators within the combustion chamber optimization with three IMEP load values: a) 3 bar, b) 6 bar, c) 11 bar 
a)

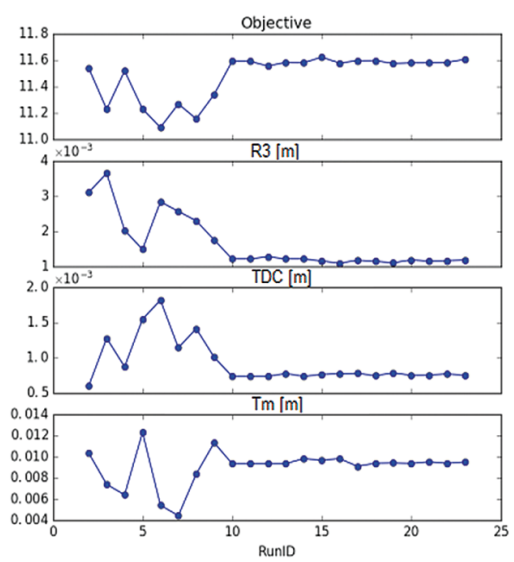

b)

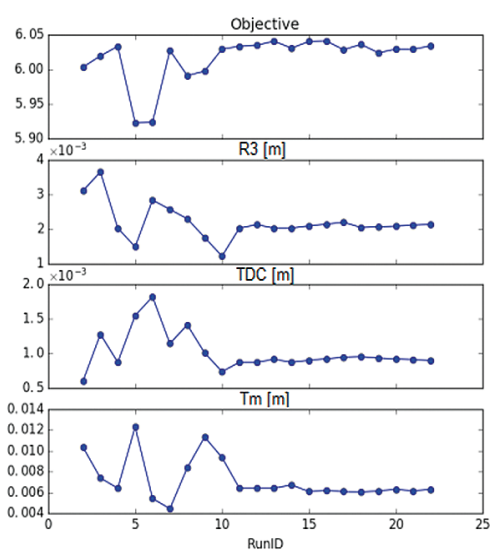

c)

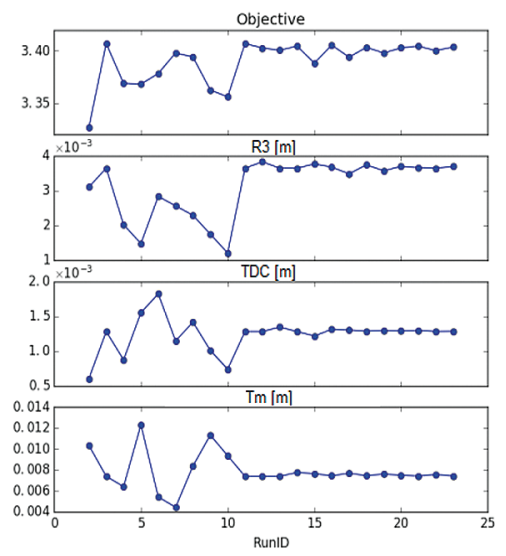

Fig. 4. One-dimensional change of three operating indicators as a part of the combustion chamber optimization with three values of the initial IMEP load: a) 3 bar, b) 6 bar, c) 11 bar

\section{THERMODYNAMIC ANALYSIS RESULTS}

Comparison of the final compression pressure values indicates significant changes in this variable when the shape (and volume) of the combustion chamber changes. The maximum and minimum values of compression pressure are the same as they result from the first 10 settings of the combustion chamber (Latin hypercube - Fig. 4 - vertical red line). These values are as follows: $P_{\text {comp }}=5.68$ and 7.07 $\mathrm{MPa}$, respectively. However, the research values are already different and result from searching for the optimal solution.

For each load, the coefficient of variation of the $\mathrm{X}$ value is determined as:

a)

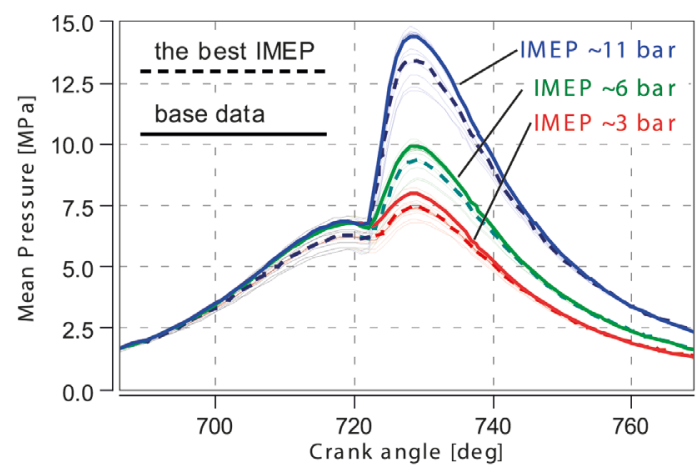

c)

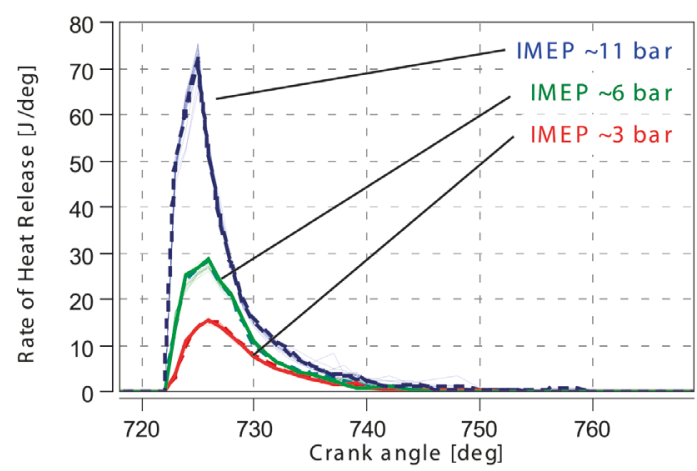

$$
\operatorname{CoV}(\mathrm{X})=\mathrm{Y}_{\mathrm{av}} / \sigma
$$

where: $\mathrm{Y}_{\mathrm{av}}$ is the mean measured value of $\mathrm{Y}, \sigma-$ standard deviation.

At low load (IMEP $=3$ bar) the coefficient of variation $\mathrm{CoV}$ (Pcomp) is $3.3 \%$, with load increase of $4.4 \%$ and $4.8 \%$, respectively. This means increasing the final compression pressure (Pcomp) together with the search for the optimum value of the indicated mean effective pressure (Fig. 5a). The change in the final compression pressure resulted in much larger changes in the maximum combustion pressure. The coefficients of variation $\operatorname{CoV}\left(\mathrm{P}_{\mathrm{mx}}\right)$ corresponding to the increased load are respectively: $2.78 \% ; 3.64 \%$ and $4.33 \%$. Similarly to $\mathrm{CoV}$ (Pcomp) also $\mathrm{CoV}(\mathrm{Pmax})$ attains higher values when increasing the load.
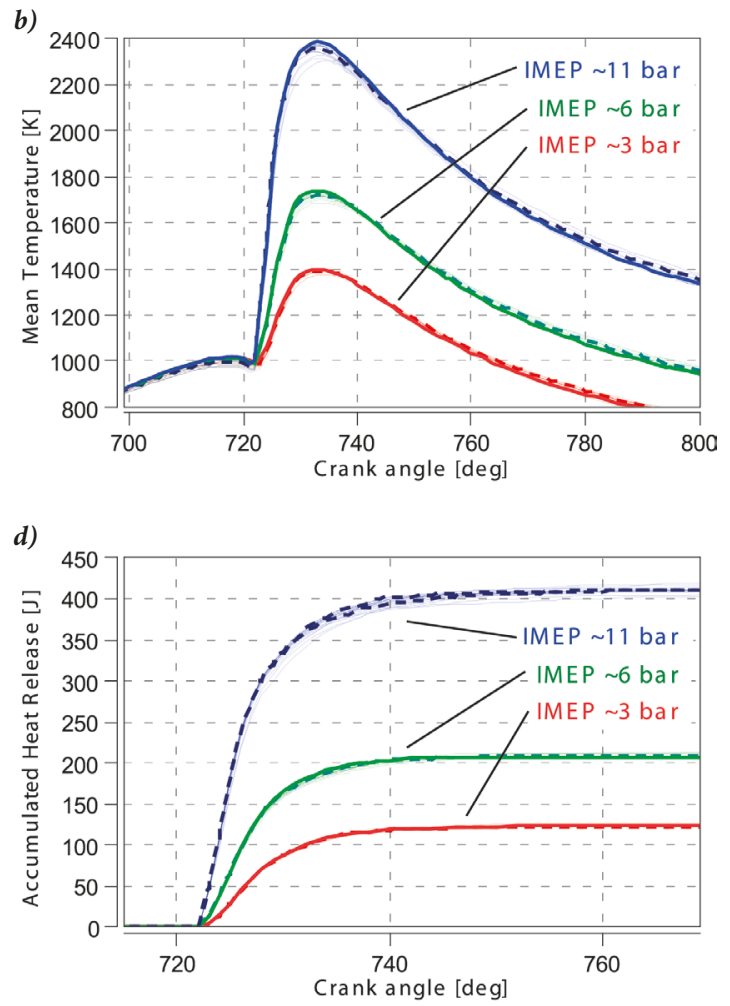

Fig. 5. Thermodynamic indicator changes of the combustion process for combustion chamber optimization with three IMEP load values: 3 bar, 6 bar, 11 bar: a) combustion pressure, $b$ ) average process temperature, $c$ ) heat recovery rate, $d$ ) heat value 
Such results indicate that it is more difficult to obtain an optimal solution at a higher load value (this is not caused by the irregularity of engine operation). Larger $\operatorname{CoV}\left(\mathrm{P}_{\max }\right.$ values when increasing the load also indicate that the initial conditions for the search of the maximum of the target function (max IMEP) adopted on the basis of the Latin hypercube are quite different.

The special feature of such procedure is also the situation that - despite different values of pressure changes in the cylinder $\left(\mathrm{P}_{\text {comp }}\right.$ and $\left.\mathrm{P}_{\max }\right)$ - other thermodynamic process indicators (temperature, heat recovery rate and heat delivered) have similar characteristics. This means that it is possible to shape the target function by using the variability of design values in a fairly wide range. The optimal values of thermodynamic indicators, marked with a dashed line, can easily be distinguished from the pressure characteristic in the cylinder, but the deviations of the remaining values from the optimal value are small (Fig. 5b-d).

Initial values of the combustion chamber design variable settings (R3, Tm, TDC) result in small changes in the internal combustion engine operating indicators. The IMEP variability coefficient at different settings takes values below $1.3 \%$ (at the maximum load) - Fig. 6a. Indicated engine efficiency is maintained at 33 to $37 \%$ (assuming maximum values at partial load) - Fig. 6b. The lowest specific fuel consumption value was obtained at the average engine load and reached $233 \mathrm{~g} / \mathrm{kWh}$. The engine mechanical efficiency increases with the load and reaches a maximum of $80 \%$ (Fig. $6 \mathrm{c}$ ). The maximum dispersion of the excess air coefficient is $\operatorname{CoV}(\lambda)=0.27 \%$, which is the smallest value analyzed.

\section{EXHAUST EMISSION ANALYSIS}

The analysis of nitrogen oxide share was based on the Extended Zeldovich model [4]. The local temperature value in the combustion chamber plays a significant role in this model. Analysis of the process mean temperature value (Figure 5b) indicates that the value of nitric oxide concentration will also be subject to high variability. The results of the NO concentration simulation are shown in Fig. 7. The values for the optimal combustion chamber fulfilling the target function indicates the NO concentration greater than the base values but still below the maximum values. It follows that it is possible to design a combustion chamber to maximize IMEP while maintaining average nitric oxide concentration values. Determining the NO emission ( expressed in $\mathrm{g} / \mathrm{kWh}$ ) should result in values below the maximum as a result of the presented characteristics changes (Fig. 7a). Similar concentration levels were obtained for greater engine loads. In both subsequent cases, the optimal chamber geometry allows obtaining NO concentration values below the maximum values (Fig. $7 \mathrm{~b}$ and $7 \mathrm{c}$ ).

The soot concentration was determined based on the kinetic model. The basis of this model is a detailed chart of chemical reactions to calculate the formation and oxidation of soot [1]. The differences in the quantities are small (Fig. 8) due to the high soot concentration in the flame in the initial combustion phase. The formation of soot in the cylinder increases with the increase in engine load. The maximum values are proportional to the engine load. Optimal dimensions of the combustion chamber (to reach the maximum value of the target function) a)

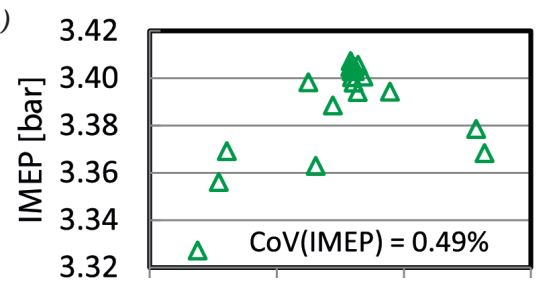

b)

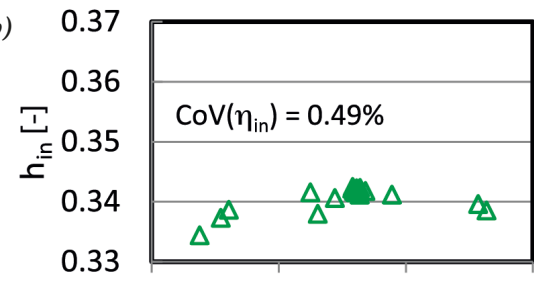

c)

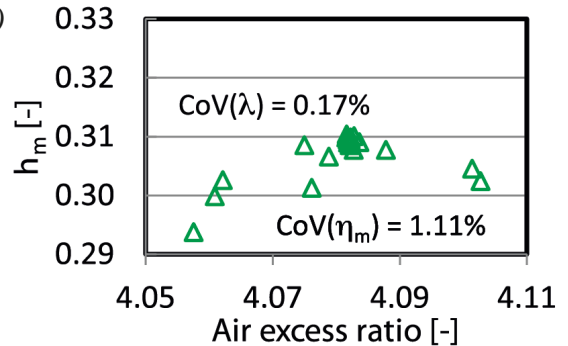

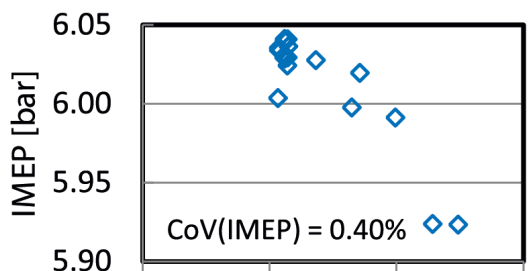
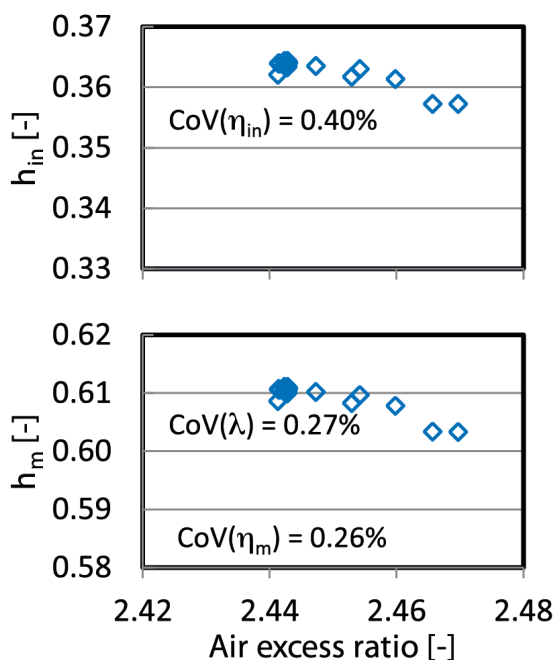
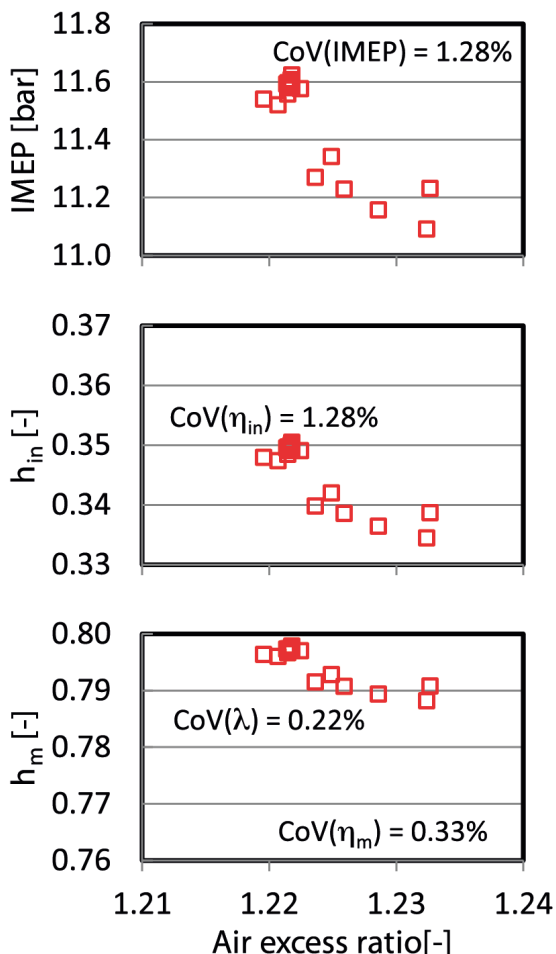

Fig. 6. Analysis of engine operating indicator changes: a) indicated mean effective pressure IMEP, $b$ ) indicated efficiency $\eta$ in, c) mechanical efficiency $\eta m$ in function of the excess air coefficient resulting from changes in the shape of the combustion chamber 
a)

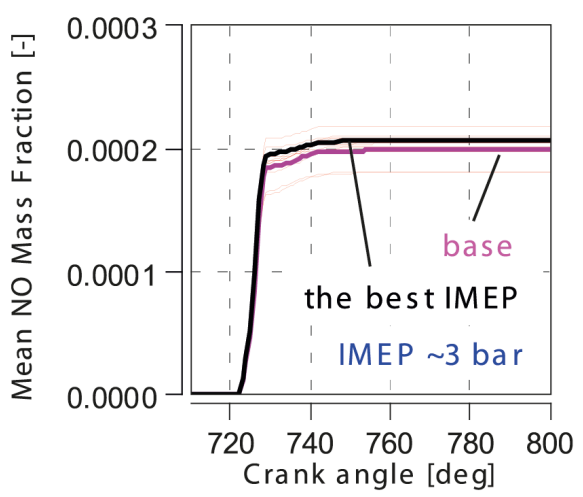

b)

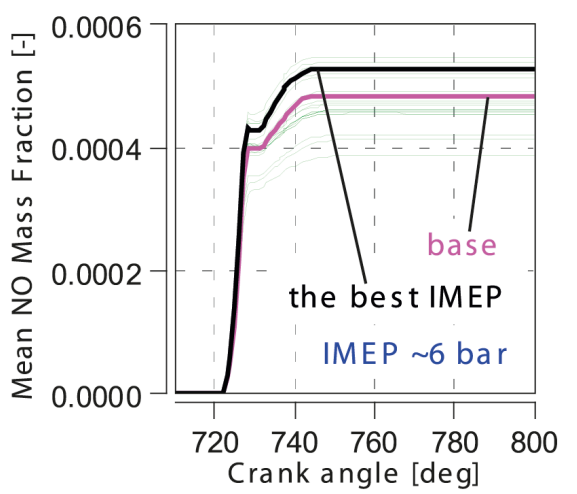

c)

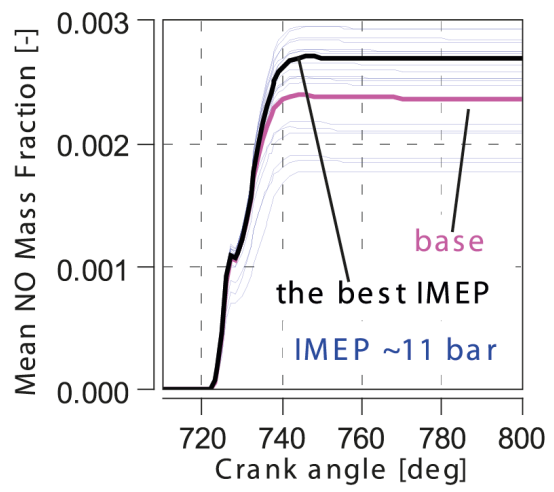

Fig. 7. Mass proportions of nitrogen oxide for various engine loads along with the initial values and corresponding to the optimal dimensions of the combustion chamber to maximize the target function: a) $I M E P=3 \mathrm{bar}, b) I M E P=6 \mathrm{bar}, c) I M E P=10 \mathrm{bar}$

a)

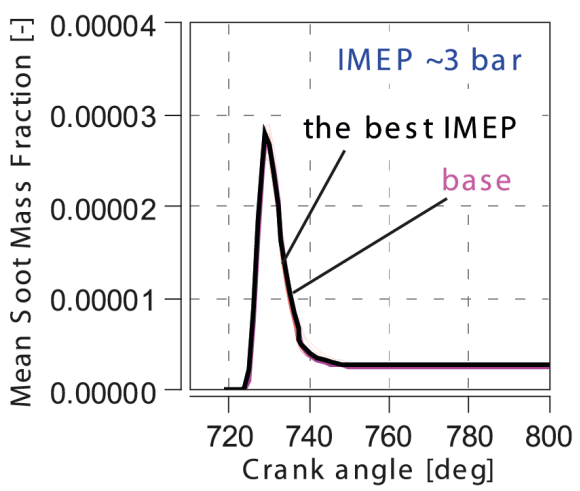

b)

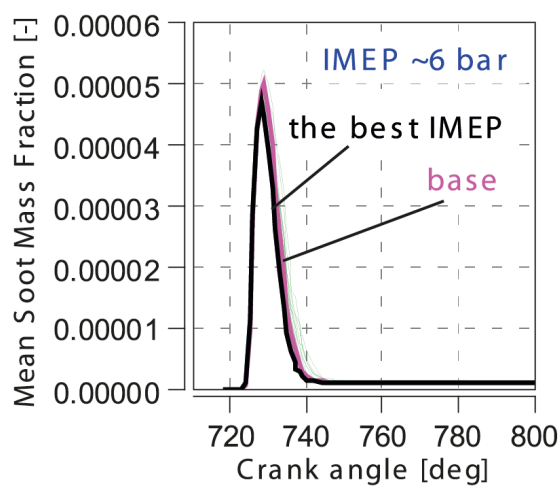

c)

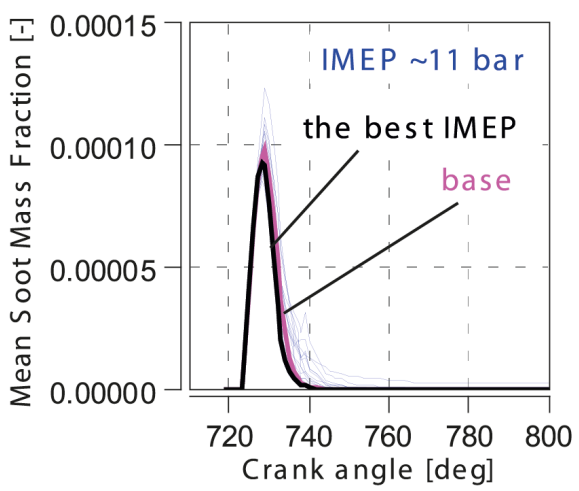

Fig. 8. Mass proportions of soot for various engine loads along with marked initial values and corresponding to optimal dimensions of the combustion chamber to maximize the target function

indicate very similar soot formation processes in the engine cylinder. There are no significant differences between the soot concentration values for the default and optimal chamber. The maximum values for the optimal chamber were found at medium and high load values, equal to $6.1 \%$ and $5.6 \%$, respectively. At the lowest load value, the concentration value increased slightly (by $3.7 \%$ ).

\section{CONCLUSIONS}

Simulation tests allow to optimize the combustion system based on accepted criteria; one of them may be the maximization of the indicated mean effective pressure (liberality of regulations concerning the exhaust emission levels related to internal combustion engines in marine applications allows to maximize operational indicators rather than emission ones).

A summary of the combustion chamber shape tests is presented in Fig. 9. The optimal variable sizes (R3, Tm and TDC) for different engine load values with the maximization of the target function (max IMEP) have been indicated.

Optimal combustion chamber designs (depending on the engine load) indicate a limitation of the so-called harmful area (TDC size) created by the compression stroke of the piston. This limits the formation of soot and hydrocarbons.
Decreasing the Tm value leads to a charge turbulence increase in the combustion chamber, increasing the intensity of the pre-flame processes resulting in an IMEP value increase. At high fuel doses, the value of R3 is limited, which allows to increase the decomposition intensity of the injected fuel droplets when interacting with the combustion chamber walls. This is confirmed by the data from Fig. 4, indicating the limitation of the radius when increasing the engine load.

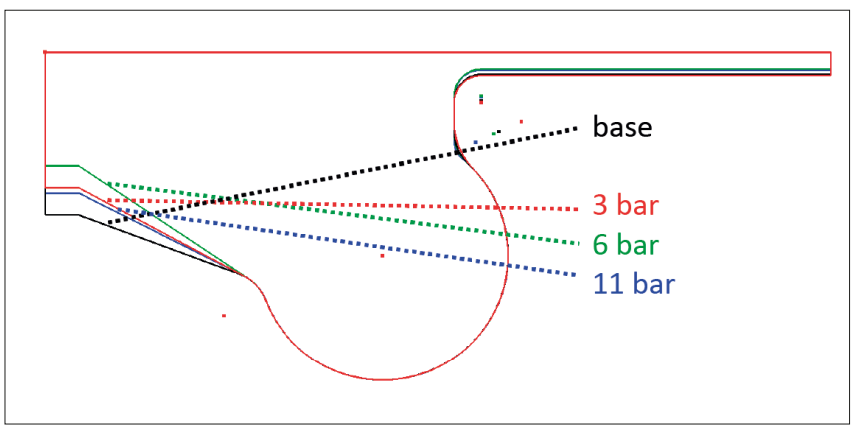

Fig. 9. Optimal combustion chamber shapes at different engine loads

This article presents an analysis of changes in selected design values in order to obtain the criterion set for which the highest values of IMEP was reached.

The results of the performed simulation tests led to the following conclusions: 
1. Optimization of combustion chamber of a internalcombustion low-speed engine in the aspect of increasing its operating indicators is a complex issue and does not lead to obtaining unambiguous variables. In the analyzed variants, the change in the engine load resulted in different optimal values of design variables.

2. The choice of the parameters R3, Tm and TDC is not unambiguous. Increasing the load causes:

a) Decreasing the value of the radius R3,

b) Reducing the TDC value,

c) An ambiguous change in the value of Tm (medium load causes a decrease of this value, but other loads increase it).

3. The analysis of optimal combustion chambers indicates that it is possible to achieve large changes in the values of compression pressure and combustion pressure; the changes do not cause large fluctuations of thermodynamic indicators in the form of: process temperature, heat release rate and heat output.

4. The sensitivity of the method was also evaluated during the analysis of nitric oxide and soot. It was found that the changes in nitric oxides are significant. In this case the differences in the extreme values reached $17 \%$ (for IMEP = 3 bar), 29\% (for IMEP = 6 bar) and 37\% (for IMEP $=11$ bar). Differences from the soot concentration analysis were found not similar to the above mentioned (the change in their values were 12\%, 14\% and 29\% respectively as the load increased).

\section{ACKNOWLEDGEMENTS}

This work has been done under AVL University Partnership Program.

\section{REFERENCES}

1. AVL FIRE, ESE Diesel, Emission Module, Version 2017.

2. Channappagoudra M., Ramesh K., Manavendra G.: Comparative study of standard engine and modified engine with different piston bowl geometries operated with B20 fuel blend. Renewable Energy, 133, 2019, pp. 216-232.

3. Gafoor A.C.P., Gupta R.: Numerical investigation of piston bowl geometry and swirl ratio on emission from diesel engines. Energy Conversion and Management, 101, 2015, pp. 541-551.

4. Heywood J.: Internal Combustion Engine Fundamentals. McGraw-Hill Book Company, New York 1988.

5. Khan S., Panua R., Bose P.K.: Combined effects of piston bowl geometry and spray pattern on mixing, combustion and emissions of a diesel engine: A numerical approach. Fuel, 225, 2018, pp. 203-217.
6. Maehara N., Shimoda Y.: Application of the genetic algorithm and downhill simplex methods (Nelder-Mead methods) in the search for the optimum chiller configuration. Applied Thermal Engineering, 61(2), 2013, pp. 433-442.

7. Marine engine programme. MAN energy solution. 2nd edition 2018. www.marine.man-es.com

8. Naber J.D., Reitz R.D. Modeling engine spray/wall impingement. SAE Technical Paper 880107.

9. Navid A., Khalilarya S., Abbasi M.: Diesel engine optimization with multi-objective performance characteristics by nonevolutionary Nelder-Mead algorithm: Sobol sequence and Latin hypercube sampling methods comparison in DoE process. Fuel, 228, 2018, pp. 349-367.

10. Pielecha I., Pielecha J., Skowron M. et al.: The influence of diesel oil improvers on indices of atomisation and combustion in high-efficiency engines. Polish Maritime Research, 3(95), vol. 24, 2017, pp. 99-105.

11. Pielecha I., Wisłocki K., Cieślik W. et al.: Application of IMEP and MBF50 indexes for controlling combustion in dual-fuel reciprocating engine. Applied Thermal Engineering, 132, 2018, pp. 188-195.

12. Shields M.D., Zhang J.: The generalization of Latin hypercube sampling, Reliability Engineering \& System Safety, 148, 2016, pp. 96-108.

13. Taghavifar H.: Towards multiobjective Nelder-Mead optimization of a HSDI diesel engine: Application of Latin hypercube design-explorer with SVM modeling approach. Energy Conversion and Management, 143, 2017, pp. 150-161.

14. Vedharaj S., Vallinayagam R., Yang W.M. et al.: Optimization of combustion bowl geometry for the operation of kapok biodiesel - Diesel blends in a stationary diesel engine. Fuel, 139, 2015, 561-567.

15. Wärtsilä Solutions for Marine and Oil \& Gas Markets. Wartsila 2018, wartsila.com. 


\section{CONTACT WITH THE AUTHORS}

Ireneusz Pielecha

e-mail:ireneusz.pielecha@put.poznan.pl

Jerzy Merkisz

e-mail: jerzy.merkisz@put.poznan.pl

Poznan University of Technology

Piotrowo 3

60-965 Poznan

Poland 